\title{
Rapid Voltammetric Screening Method for the Assessment of Bioflavonoid Content Using the Disposable Bare Pencil Graphite Electrode
}

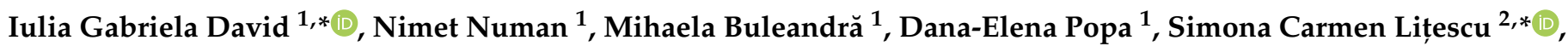 \\ Sorin Riga ${ }^{3}$ and Adela Magdalena Ciobanu ${ }^{4,5}$ (D) \\ 1 Department of Analytical Chemistry, Faculty of Chemistry, University of Bucharest, Panduri Av. 90-92, \\ District 5, 050663 Bucharest, Romania; numannimet097@gmail.com (N.N.); \\ mihaela.buleandra@g.unibuc.ro (M.B.); elena.popa@chimie.unibuc.ro (D.-E.P.) \\ 2 National Institute of Research and Development for Biological Sciences, 296 Independenței Bd., District 6, \\ 060031 Bucharest, Romania \\ 3 Department of Stress Research \& Prophylaxis, “Prof. Dr. Al. Obregia” Clinical Hospital of Psychiatry, \\ Berceni Av. 10, District 4, 041914 Bucharest, Romania; d_s_riga@yahoo.com \\ 4 Department of Psychiatry, "Prof. Dr. Al. Obregia" Clinical Hospital of Psychiatry, Berceni Av. 10, District 4, \\ 041914 Bucharest, Romania; adela.ciobanu@gmail.com \\ 5 Discipline of Psychiatry, Neurosciences Department, Faculty of Medicine, "Carol Davila" University of \\ Medicine and Pharmacy, Dionisie Lupu Street 37, 020021 Bucharest, Romania \\ * Correspondence: gabrielaiulia.david@g.unibuc.ro (I.G.D.); slitescu@gmail.com (S.C.L.)
}

\section{check for} updates

Citation: David, I.G.; Numan, N.; Buleandră, M.; Popa, D.-E.; Lițescu, S.C.; Riga, S.; Ciobanu, A.M. Rapid Voltammetric Screening Method for the Assessment of Bioflavonoid Content Using the Disposable Bare Pencil Graphite Electrode. Chemosensors 2021, 9, 323. https:// doi.org/10.3390/chemosensors9110323

Academic Editors: Run Zhang and Daniele Merli

Received: 1 September 2021

Accepted: 16 November 2021

Published: 18 November 2021

Publisher's Note: MDPI stays neutral with regard to jurisdictional claims in published maps and institutional affiliations.

Copyright: (c) 2021 by the authors. Licensee MDPI, Basel, Switzerland. This article is an open access article distributed under the terms and conditions of the Creative Commons Attribution (CC BY) license (https:/ / creativecommons.org/licenses/by/ $4.0 /)$.
Abstract: Hesperidin (HESP) is a plant bioflavonoid found in various nutritional and medicinal products. Many of its multiple health benefits rely on the compound's antioxidant ability, which is due to the presence of oxidizable hydroxyl groups in its structure. Therefore, the present study aimed to investigate the electrochemical behavior of HESP at a cheap, disposable pencil graphite electrode (PGE) in order to develop rapid and simple voltammetric methods for its quantification. Cyclic voltammetric investigations emphasized a complex electrochemical behavior of HESP. The influence of the electrode material, solution stability, supporting electrolyte $\mathrm{pH}$, and nature were examined. HESP main irreversible, diffusion-controlled oxidation signal obtained at $\mathrm{H}$ type PGE in Britton Robinson buffer $\mathrm{pH} 1.81$ was exploited for the development of a differential pulse voltammetry (DPV) quantitative analysis method. The quasi-reversible, adsorption-controlled reduction peak was used for HESP quantification by differential pulse adsorptive stripping voltammetry (DPAdSV). The linear ranges of DPV and DPAdSV were $1.00 \times 10^{-7}-1.20 \times 10^{-5}$ and $5.00 \times 10^{-8}-1.00 \times 10^{-6} \mathrm{~mol} / \mathrm{L}$ with detection limits of $8.58 \times 10^{-8}$ and $1.90 \times 10^{-8} \mathrm{~mol} / \mathrm{L} \mathrm{HESP}$, respectively. The DPV method was applied for the assessment of dietary supplements bioflavonoid content, expressed as mg HESP.

Keywords: pencil graphite electrode; voltammetry; hesperidin; bioflavonoids; antioxidant; dietary supplements

\section{Introduction}

Hesperidin (HESP), 3', 5, 7-trihydroxy-4'methoxyflavanone-7-rutinoside, (Figure 1) is a bioflavonoid (glycosidic flavanone) abundant (mainly in the peal and white part) in Citrus species (Rutaceae family) like the common orange, lemon, etc., but it can also be found in other different plants, including peppermint [1]. HESP and its aglycone hesperetin have a wide range of biological effects due to their immune-stimulant, antimicrobial, antioxidant [2], anti-inflammatory, anti-infertility, UV-protecting, anti-allergic, anti-nociceptive, anticonvulsant [3], and anti-aging properties [4]. HESP administration decreases the capillaries permeability and increases their resistance, thus being benefic in blood vessel disorders such as hemorrhoids, varicose veins [5], oedema, hemorrhage, pleurisy, Henoch-Schönlein purpura, and tuberculosis [3]. On the other hand, it is largely 
employed as a treatment in a variety of cardio-vascular diseases [6]. Extrinsic and intrinsic apoptosis and the growth inhibitions of several malignant cells are mediated by HESP, this bioflavonoid being effective against various cancers, including leukemia and colon, gastric, liver, cervix, breast, and lung cancer [3,7]. Taking into consideration that HESP appears to have an inhibitory effect on obesity illnesses by regulating lipid and glucose metabolism, dietary supplements containing it also help to reduce symptoms such as postprandial hyperglycemia and hyperlipidemia [1,8]. Acting through different mechanisms, HESP has benefic effects in diabetic retinopathy [9]. Due to its antioxidant and biomembrane stabilization properties, HESP can exert protective effects in Parkinson's disease models. It reduces the depressive symptoms by modulating the kappa-opioid and serotonergic $5-\mathrm{HT}_{1 \mathrm{~A}}$ receptors [3]. HESP antidepressant effect was demonstrated on mice exposed to chronic unpredictable mild stress [10]. Based on its powerful memory-enhancing and antioxidant benefits, it has the potential to be used as a treatment for Alzheimer's disease and dementia. HESP capacity to boost anti-oxidative defense might be one of the processes involved in cognitive function improvement [3]. Besides this, HESP anti-oxidant and antiinflammatory effects are benefic in different central nervous system disorders emphasizing its nutraceutical use for their prevention and currying [11].

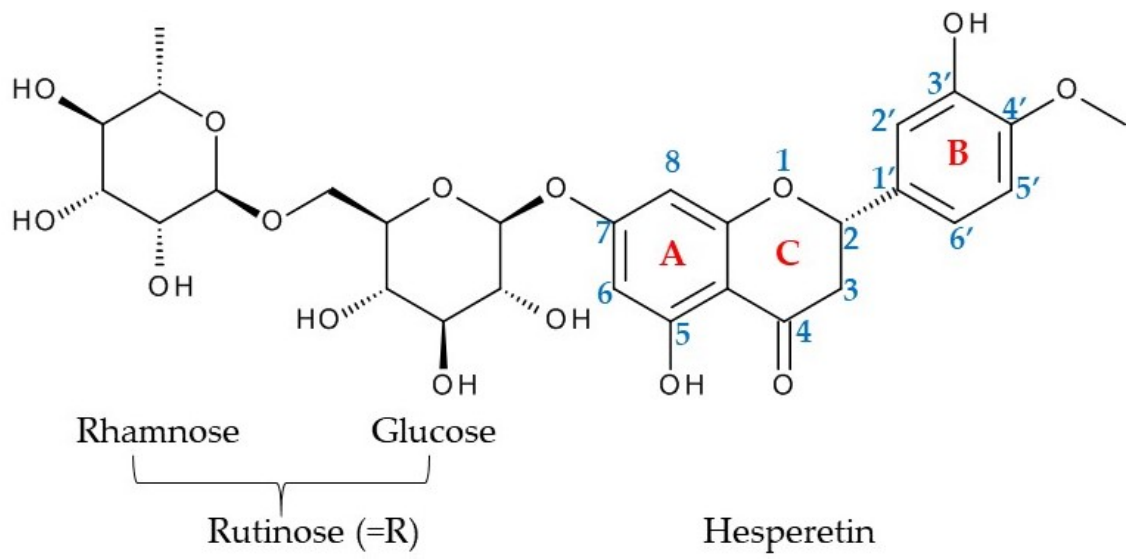

Figure 1. Chemical structure of hesperidin (HESP).

HESP anti-replicative effect against several viruses was also discovered [3]. It was recently shown that HESP interacts with the proteins of the severe acute respiratory syndrome coronavirus 2 (SARS-CoV-2). It binds to both the central part of the coronavirus "spike" glycoprotein and to the main protease. With the binding energy being low, the bonds are stronger than in the case of common antivirals. On the other hand, HESP antioxidant properties help in reducing cell damage generated by virus infection and inflammation. Thus, in the near future, HESP, like quercetin, may be tested as an antiviral agent in randomized trials of COVID-19 patients [2].

Hesperidin may be produced using readily available, plentiful, and inexpensive biological resources, and it appears to be promising for the creation of nutritional, nutraceutical, and medicinal products [1].

The antioxidant activity of bioflavonoids in general, and HESP in particular, is based on their ability to donate electrons/protons, thus scavenging the free radicals and terminating chain reactions. This chemical property of high biological significance is due to the oxidizable hydroxyl groups present in their molecular structures. It is well-known that there is a correlation between the antioxidant efficiency and how easy it is to be oxidized for a species, reflected in its electrochemical parameters, mainly the oxidation potentials (obtained most often by cyclic voltammetry), i.e., a lower oxidation potential indicates a higher scavenging capability and thus higher potential antioxidant effectiveness. Therefore, electroanalysis is one of the most important tools for the quick and simple assessment of a species' antioxidant effectiveness and could help understanding some redox governed bio- 
logical processes, giving insight in the reaction kinetics and number of involved electrons and protons. Various (bio)sensors are continuously developed for many analytes with biological and clinical significance and consequently electrochemical (bio)sensing became a low-cost and rapid prognostic and monitoring tool for different diseases, including also COVID-19 [12,13].

HESP usually coexists in complex matrices with other structurally related compounds and therefore its analysis is often performed by different chromatographic techniques $[14,15]$, which possesses high selectivity, but involves expensive equipment, significant quantities of solvents, is laborious and time-consuming. In turn, electroanalytical techniques can be performed in colored or turbid solutions, are more rapid and environmental friendly (less reagents consumption), use less expensive instrumentation, offering good sensitivity and selectivity, with no or only simple sample preparation procedures. The first electrochemical investigations of flavonoids were based on their reduction at mercury electrodes, but the presence of the hydroxyl groups in their structure enables also their electrooxidation. This was investigated since the 1980s, starting with the glassy carbon electrode (GCE) [16] and employing many other electrodes either bare [5,17-19], electroactivated $[20,21]$ or modified with different carbon based materials like carbon nanotubes [22-24] or graphene derivatives [25-28], nanomaterials [26,28-30], polymeric films $[27,28,31]$, etc. Unfortunately, most of the electrodes encounter problems due to the electroactive surface fouling during the electrochemical investigations, especially when these are based on the oxidation of phenolic compounds, which can generate phenoxy radicals able to polymerize and produce a film covering the electrode surface. On the other hand, the preparation of chemically modified electrodes involves time-consuming steps and additional reagents. These drawbacks can be minimized by using simple, cost-effective, and easy renewable working electrodes, like the pencil graphite electrode (PGE). Therefore, despite the fact that there is a huge number of papers published regarding the use of PGEs as working electrodes for the electroanalysis of very different species, only a recent paper [21] describes a differential pulse voltammetry (DPV) method for HESP determination using an electroactivated PGE. However, the present work brings forward a simpler and even more sensitive DPV assay using an unmodified and non-activated PGE. The current electroanalytical method is eco-friendly due to the reduced consume of reagents, more rapid (no required electroactivation or other electrode surface modification steps), and has a lower limit of detection $\left(8.58 \times 10^{-8} \mathrm{~mol} / \mathrm{L}\right.$ compared to $2.00 \times 10^{-7} \mathrm{~mol} / \mathrm{L}$ [21] $)$ and a wider linear range $\left(1.00 \times 10^{-7}-1.20 \times 10^{-5} \mathrm{~mol} / \mathrm{L}\right.$ vs. $5.00 \times 10^{-7}-1.00 \times 10^{-5} \mathrm{~mol} / \mathrm{L}$ [21] $)$ achieved by the proper selection of the graphite pencil lead type and supporting electrolyte. The limit of detection was further decreased $\left(1.90 \times 10^{-8} \mathrm{~mol} / \mathrm{L}\right)$ by exploiting HESP reduction signal after the analyte adsorptive accumulation at positive potentials, being thus better than LODs attained with some modified working electrodes [30,32]. The simple and cost-effective developed DPV method at a cheap disposable bare PGE (one graphite lead costed about 0.03 Euro) was successfully applied to the fast determination of the citrus bioflavonoids content, expressed as mg HESP, from a complex dietary supplement. Therefore, the novelty of this study consists in the employment, for the first time, of the PGE in the HESP determination, without any modification procedure, but with a good sensitivity and acceptable selectivity, thus being useful as a rapid screening analytical tool of total bioflavonoid content from pharmaceuticals or dietary supplements.

\section{Materials and Methods}

\subsection{Reagents and Solutions}

Hesperidin (HESP) (90\%), $\mathrm{H}_{2} \mathrm{SO}_{4}\left(98 \%\right.$, ACS reagent), $\mathrm{NaOH}$ (pellets), $\mathrm{KH}_{2} \mathrm{PO}_{4}$ and $\mathrm{Na}_{2} \mathrm{HPO}_{4} \times 2 \mathrm{H}_{2} \mathrm{O}$ (p.a. ACS reagent), $\mathrm{H}_{3} \mathrm{BO}_{3}(1 \mathrm{~g} /$ tablet), acetic acid ( $\geq 97 \%$, ACS reagent), $\mathrm{H}_{3} \mathrm{PO}_{4}$ ( $\geq 85 \mathrm{wt}$. \% in water, ACS reagent), $\mathrm{HCl}$ (37\%, ACS reagent), and $\mathrm{HNO}_{3}(70 \%$, ACS reagent) were purchased from Sigma-Aldrich (St. Louis, MO, USA).

The $1.00 \times 10^{-3} \mathrm{~mol} / \mathrm{L}$ HESP stock solution was every time freshly prepared at the beginning of each set of measurements by dissolving the accurately weighted appropriate 
mass of analyte in $2.50 \mathrm{~mL} 0.20 \mathrm{~mol} / \mathrm{L} \mathrm{NaOH}$ and diluting with deionized water to $10.00 \mathrm{~mL}$. In the day of preparation, this solution was maintained in the refrigerator when not in use. More diluted working solutions with concentrations ranging from $2.50 \times 10^{-8}$ to $1.00 \times 10^{-4} \mathrm{~mol} / \mathrm{L}$ HESP were prepared just before the voltammetric recordings from the stock solution by successive dilutions with deionized water, the last dilution being carried out with the proper supporting electrolyte to the mark of a $10.00 \mathrm{~mL}$ volumetric flasks.

The universal Britton Robinson buffer (BRB) with $\mathrm{pH}$ values between 1.81 and 11.58 was used to investigate the $\mathrm{pH}$ influence on the HESP voltammetric response.

The dietary supplement Good Routine C-Your-Immunity from Secom Healthcare S.R.L. Romania containing $250 \mathrm{mg}$ vitamin C, $250 \mathrm{mg}$ quercetin, $25 \mathrm{mg}$ bromelain, $10 \mathrm{mg}$ citrus bioflavonoids (from Citrus Sinensis fruits) with $60 \%$ hesperidin was purchased from a local natural products store.

\subsection{Instrumentation}

Voltammograms were recorded on an Autolab PGSTAT 12 galvanostat-potentiostat coupled to a PC equipped with the GPES 4.9 software for experimental control and data acquisition. A $50 \mathrm{~mL}$ single compartment voltammetric glass cell consisting of a threeelectrode system was used. A platinum (Pt), glassy carbon electrode (GCE) $(0.30 \mathrm{~cm}$ diameter and $0.0711 \mathrm{~cm}^{2}$ geometrical surface area) or a pencil-graphite electrode (PGE) acted as working electrode, a Pt wire as auxiliary and $\mathrm{Ag} / \mathrm{AgCl}(3 \mathrm{~mol} / \mathrm{L} \mathrm{KCl})$ as reference electrode, respectively. The voltammetric measurements were carried out at room temperature $\left(21 \pm 2{ }^{\circ} \mathrm{C}\right)$, on $10 \mathrm{~mL}$ sample solutions containing the supporting electrolyte and the analyte. Automatic background correction using GPES 4.9. software was performed for each registered voltammogram.

In order to ensure a reproducible surface, before each measurement the solid electrodes (GCE and Pt) were cleaned with alumina powder, rinsed with deionized water, and dried with filter paper.

The PGE was prepared as previously described [33] using commercially available Rotring graphite pencil leads with the diameter of $0.05 \mathrm{~cm}$ and a Rotring mechanical pencil acting as holder. The electrical contact between the lead and the instrument was realized by soldering a metal wire to the metallic part of the pencil holder. The active surface area of the PGE was a composite graphite pencil lead of different hardness $(2 \mathrm{H}, \mathrm{H}, \mathrm{HB}, \mathrm{B}$, and 2B). Every time, $1.00 \mathrm{~cm}$ of the graphite lead was introduced into the analyzed solution, so that a constant active electrode area $\left(0.1590 \mathrm{~cm}^{2}\right.$ geometrical area) was assured. If not stated otherwise, a new graphite pencil lead was employed for each measurement.

A Consort P901Scientific Instrument $\mathrm{pH} / \mathrm{mV} /{ }^{\circ} \mathrm{C}$-meter (Belgium) equipped with a combined $\mathrm{pH}$-sensitive glass electrode was employed for the $\mathrm{pH}$ measurements of the analyzed solutions.

\subsection{Procedures}

The studies regarding the voltammetric behavior of HESP at PGE were performed by cyclic voltammetry $(\mathrm{CV})$ and differential pulse voltammetry (DPV) in the potential range 0.000 to $1.500 \mathrm{~V}$, whereas DPV and differential adsorptive pulse voltammetry (DPAdSV) were used for HESP quantitative determination. DPV and the standard addition method were applied for recovery studies and for the assessment of bioflavonoids content, expressed as mg HESP, of dietary supplements.

Four whole Good Routine C-Your-Immunity gelatinous capsules containing $10 \mathrm{mg}$ bioflavonoids/capsule were first dissolved in $10 \mathrm{~mL} 0.2 \mathrm{~mol} / \mathrm{L} \mathrm{NaOH}$ solution and approximately $100 \mathrm{~mL}$ deionized water, sonicated for $15 \mathrm{~min}$, and filtered through a Whatman filter paper. For the complete recovery of the analyte, the filter paper was washed five times with small volumes of deionized water. The filtrate and the washing solutions were collected in a $200 \mathrm{~mL}$ volumetric flask and brought to the mark with deionized water. Aliquots of $0.06 \mathrm{~mL}$ of this solution were diluted to $10 \mathrm{~mL}$ with $\mathrm{BRB} \mathrm{pH} 1.81$ in order to reduce the matrix effects $[34,35]$ and to bring the sample concentration in the linear range 
of the applied DPV analysis method. The standard addition method (three successive additions of $0.025 \mathrm{~mL}$ of $4.00 \times 10^{-4} \mathrm{~mol} / \mathrm{L}$ HESP standard solution) was employed for the assessment of the capsules' bioflavonoids content expressed as $\mathrm{mg}$ hesperidin.

\section{Results and Discussion}

\subsection{Selection of the Optimum Measurement Conditions}

\subsubsection{The Working Electrode}

The first step in the development of an electrochemical method is the selection of the working electrode, since the nature of the working electrode and its electroactive surface area strongly influences both the electrochemical behavior of an analyte and the sensitivity of the response. The reproducibility of the voltammetric measurements depends a lot on the reproducibility of the sensors' electroactive surface, which, in the case of solid electrodes, is ensured by some tedious and time consuming cleaning steps carried out before each new recording. This drawback can be avoided by using cost-effective, disposable working electrodes, like the PGEs. The active part of the PGE is represented by a graphite lead usually employed for common writing. Graphite pencil leads are composite materials containing graphite, clay, or a high polymer (binder) and wax (lubricant). The hardness and, therefore, the lettering of the graphite pencil leads depend on the mass ratio between graphite and clay/high polymer. According to the European Letter Scale, the leads having more graphite (noted with $\mathrm{B}$ ) are softer (9B is the softest) and darker, the harder ones being noted with $\mathrm{H}(9 \mathrm{H}$ is the hardest), whereas $\mathrm{HB}$ is in the middle of this hierarchy [20]. Thus, DP voltammograms were recorded for HESP in BRB pH 1.81 at the commonly used solid electrodes, GCE and $\mathrm{Pt}$, as well as at the cost-effective, disposable PGE using graphite leads of different hardness $(2 \mathrm{H}, \mathrm{H}, \mathrm{HB}, \mathrm{B}$, and $2 \mathrm{~B})$ from the same manufacturer (Figure 2). In BRB solution, $\mathrm{pH} 1.81$ HESP presented two well defined oxidation peaks $\left(\mathrm{E}_{\mathrm{pa} 2} \sim 0.715 \mathrm{~V}\right.$ and $\left.\mathrm{E}_{\mathrm{pa} 3} \sim 1.100 \mathrm{~V}\right)$ at all PGEs, the highest being at $\mathrm{H}$ type PGE and a very low signal at GCE. HESP peaks recorded at PGE appear at somewhat lower potentials and are higher than at GCE probably due to the more porous graphite/high polymer composite material, which may have a catalytic effect on the analyte oxidation. This effect was also reported for the electrooxidation of other phenolic species [36]. The enhancement of the peak currents is also a result of the higher geometrical electroactive surface area. At the Pt electrode, there are two anodic signals: the one situated at less positive potentials did not change with HESP concentration, whereas the very broad one from more positive potentials represented the two HESP oxidation signals (a2 and a3) observed at the PGE, which are not resolved at the Pt surface. As the voltammetric signal depends on the surface area of the working electrode and on the analyte concentration, the response sensitivity (S) of each electrode type was assessed for the same concentration level, in order to establish the electrochemical suitability of the electrode material for the considered bioflavonoid quantification. The HESP higher oxidation signal (a2, with the peak potential $\mathrm{E}_{\mathrm{pa} 2} \sim 0.710 \mathrm{~V}$ ) was used. The enhanced sensitivities obtained at PGEs vs. the GCE can be attributed to the rougher PGE surface in comparison to that of the GCE [37]. According to the results shown in Table 1, the best sensitivity was also achieved at the H type PGE and therefore, this electrode was used in all the further voltammetric investigations of HESP. 


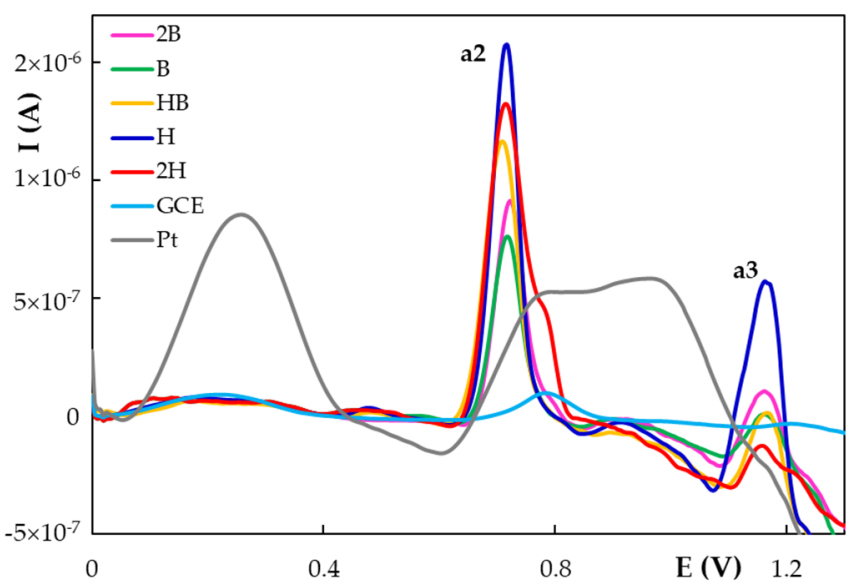

Figure 2. Differential pulse voltammograms recorded at different working electrodes for $4.00 \times 10^{-6}$ mol/L HESP in BRB solution $\mathrm{pH} 1.81$.

Table 1. Peak potentials $\left(\mathrm{E}_{\mathrm{pa} 2}\right)$ and sensitivities $(\mathrm{S})$ of $4.00 \times 10^{-6} \mathrm{~mol} / \mathrm{L}$ HESP main oxidation signal (a2) obtained in BRB solution $\mathrm{pH} 1.81$ by DPV at various working electrodes.

\begin{tabular}{ccc}
\hline Working Electrode & $\mathbf{E}_{\mathbf{p a} \mathbf{2}}(\mathbf{V})$ & $\mathbf{S}\left(\mathbf{A} \times \mathbf{L} / \mathbf{m o l} \times \mathbf{c m}^{\mathbf{2}}\right)$ \\
\hline $\mathrm{PGE} / 2 \mathrm{~B}$ & 0.722 & 1.501 \\
$\mathrm{PGE} / \mathrm{B}$ & 0.715 & 1.255 \\
$\mathrm{PGE} / \mathrm{HB}$ & 0.708 & 1.918 \\
$\mathrm{PGE} / \mathrm{H}$ & 0.715 & 2.563 \\
$\mathrm{PGE} / 2 \mathrm{H}$ & 0.715 & 2.201 \\
$\mathrm{GCE}$ & 0.742 & 0.411 \\
$\mathrm{Pt}$ & no characteristic peak & \\
\hline
\end{tabular}

The sensitivity and selectivity of the electrodes could be enhanced by modifying their surface and the simplest way to do this is the electrochemical pretreatment (electroactivation), which consists in applying (potentiostatically or potentiodynamically) extreme potentials to the working electrode, using different supporting electrolytes. During these processes, the electrode's electrochemical properties could be changed due to the fact that its surface is electrochemically activated by cleaning and by generation of some oxygen-containing groups, which may interact with the analyte [20]. Experimental results (Supplementary Material) revealed that the PGE electroactivation did not improve the sensitivity of HESP DPV oxidation signal. Therefore, in the next steps of this study, a non-electroactivated H type PGE was employed. Despite the fact that PGE is disposable and very cheap, the possibility of using the same graphite lead for more measurements was tested by recording successive cyclic voltammograms at the same PGE. As the currents of the oxidation peaks (Figure 3) decreased after the first scan, it was obvious that a pencil lead cannot be used for multiple recordings. Therefore, during the further investigations each voltammetric measurement was performed using as working electrode, a new, non-activated graphite pencil lead, if it was not stated otherwise.

\subsubsection{Solutions and Supporting Electrolyte}

Another important chemical parameter that influences the electrochemical behavior of an analyte is the supporting electrolyte. Consequently, both the influence of the $\mathrm{pH}$ and of the nature of the supporting electrolyte were investigated. The $\mathrm{pH}$ of the solution affects the voltammetric response of a compound, especially organic derivatives, whose electrode processes most often also involve protons. Therefore, the effect of the solution $\mathrm{pH}$ on HESP electrooxidation was examined by DPV in BRB solutions with different $\mathrm{pH}$ values between 1.81 and 11.58 (Figure 4a). As was expected, by increasing the solution $\mathrm{pH}$, HESP anodic peaks shifted in the cathodic direction, suggesting that protons also participated 
in the electrode processes. The slope values of the $E_{p a}=f(p H)$ dependencies (where $E_{p a}$ represents the anodic peak potential, with $\mathrm{E}_{\mathrm{pa} 2}$ and $\mathrm{E}_{\mathrm{pa} 3}$ the peak potentials of peak $\mathrm{a} 2$ and $\mathrm{a} 3$, respectively) (Figure $4 \mathrm{~b}$ ) were close to the theoretical one of $0.059 \mathrm{~V} / \mathrm{pH}$ from the Nernst equation, indicating that in the HESP oxidation reactions, an equal number of protons and electrons were transferred.

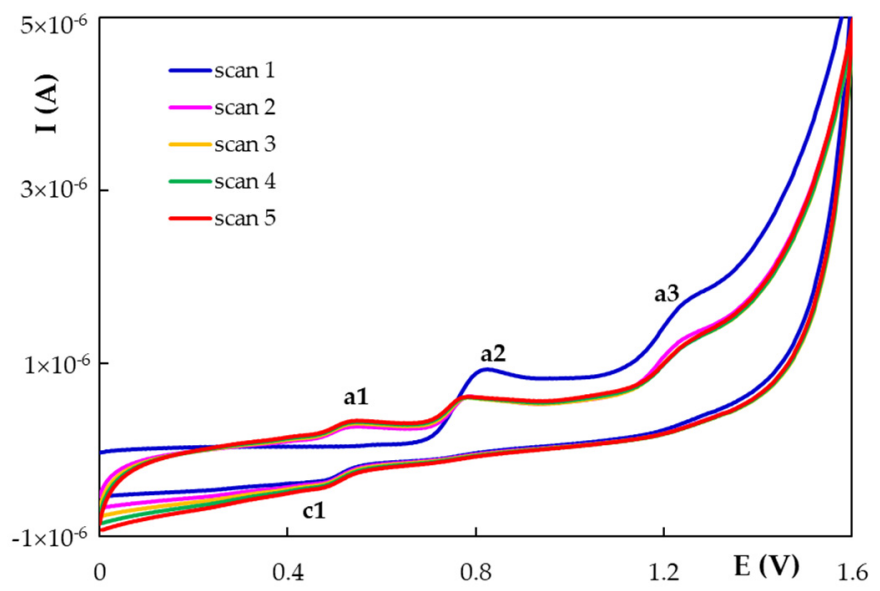

Figure 3. The first five successive cyclic voltammetric scans recorded at $\mathrm{H}$ type PGE for $1.00 \times 10^{-4} \mathrm{~mol} / \mathrm{L}$ HESP in BRB solution $\mathrm{pH} 1.81$; scan rate $0.100 \mathrm{~V} / \mathrm{s}$.
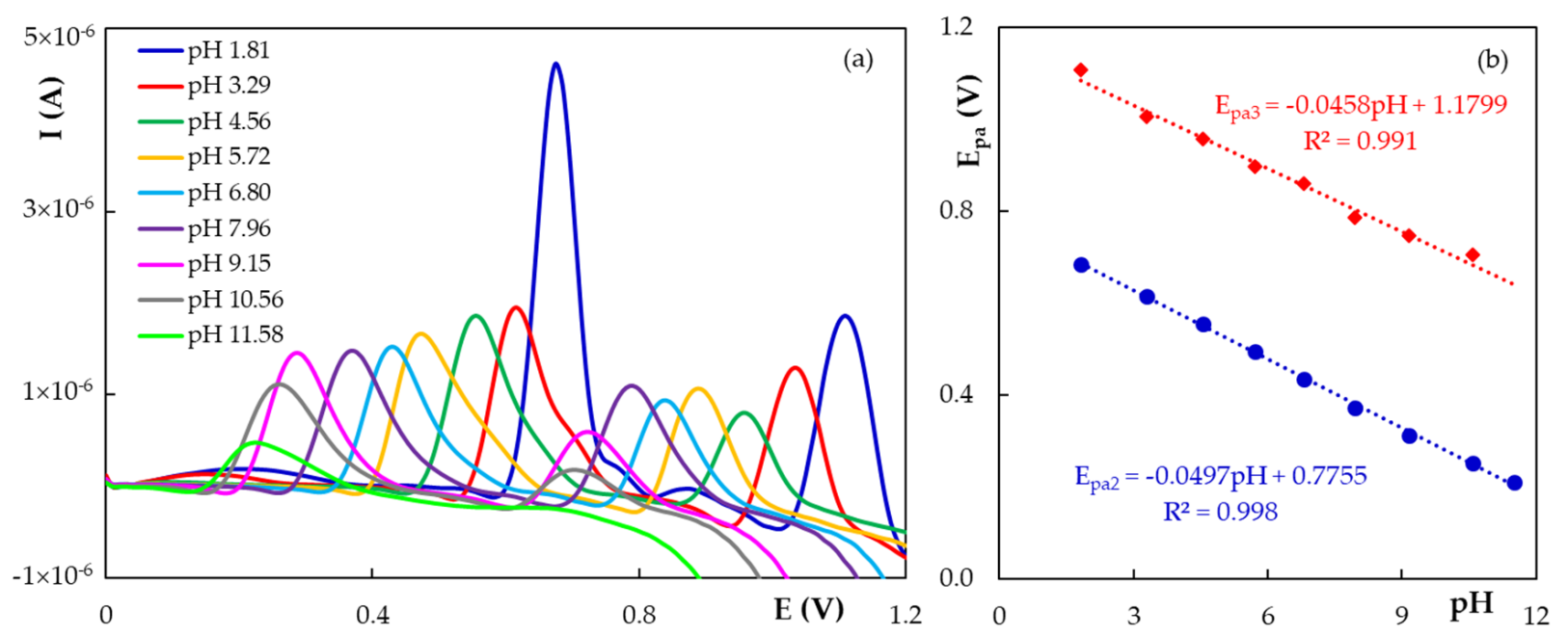

Figure 4. (a) Differential pulse voltammograms recorded at $\mathrm{H}$ type PGE for $5.00 \times 10^{-5} \mathrm{~mol} / \mathrm{L}$ HESP in BRB solutions with different $\mathrm{pH}$ values and $(\mathbf{b})$ the corresponding $\mathrm{E}_{\mathrm{pa}}=\mathrm{f}(\mathrm{pH})$ dependencies for the two HESP oxidation peaks.

According to Figure 4a, the highest anodic signal was recorded in BRB solution $\mathrm{pH} 1.81$, these findings being in accordance to the data previously reported in the literature for HESP oxidation at carbon-based [16,23] and boron-doped diamond electrodes [5]. This is supported by the general behavior of flavonoids at extremely low $\mathrm{pH}$ values determined by the resonance effect on active $\mathrm{OH}$ groups, which are preserving the antioxidant effect of flavonoids due to stabilization of flavylium cation. Therefore, the influence of the supporting electrolyte nature on HESP DPV response at $\mathrm{H}$ type PGE was tested (not shown) using also other acidic media like $0.1 \mathrm{~mol} / \mathrm{L} \mathrm{HCl}, 0.1 \mathrm{~mol} / \mathrm{L} \mathrm{HNO}_{3}$ and $0.1 \mathrm{~mol} / \mathrm{L}$ $\mathrm{H}_{2} \mathrm{SO}_{4}$, but the most intense peaks were obtained in $\mathrm{BRB} \mathrm{pH} 1.81$ and hence this solution was used as supporting electrolyte in the further HESP voltammetric investigation.

Studies regarding the HESP solutions stability pointed out that the hesperidin stability in the given conditions (see Supplementary Materials) did not affect the voltammetric results 
since both stock and working solutions were always freshly prepared and, on the other hand, the analyzed solutions had usually HESP concentrations up to $5.00 \times 10^{-5} \mathrm{~mol} / \mathrm{L}$.

\subsection{Hesperidin Voltammetric Behavior at the Pencil Graphite Electrode}

Cyclic voltammetry performed at different scan rates was employed for the investigation of HESP voltammetric behavior in BRB solution $\mathrm{pH}$ 1.81. Two potential cycles were recorded at $\mathrm{H}$ type PGE in the potential range 0.000 to $1.500 \mathrm{~V}$, applying different scan rates $(0.010$ to $0.500 \mathrm{~V} / \mathrm{s})$. Figure $5 \mathrm{a}$ indicates that in the first forward cyclic voltammetric scan HESP presented a well-defined anodic signal at $\sim 0.800 \mathrm{~V}$ (a2) and at scan rates higher than $0.050 \mathrm{~V} / \mathrm{s}$ a second one appeared at $\sim 1.230 \mathrm{~V}$ (a3). These two peaks were observed also in the next consecutive scans, but they were less intense (Figure 3) and were due to irreversible oxidation processes.
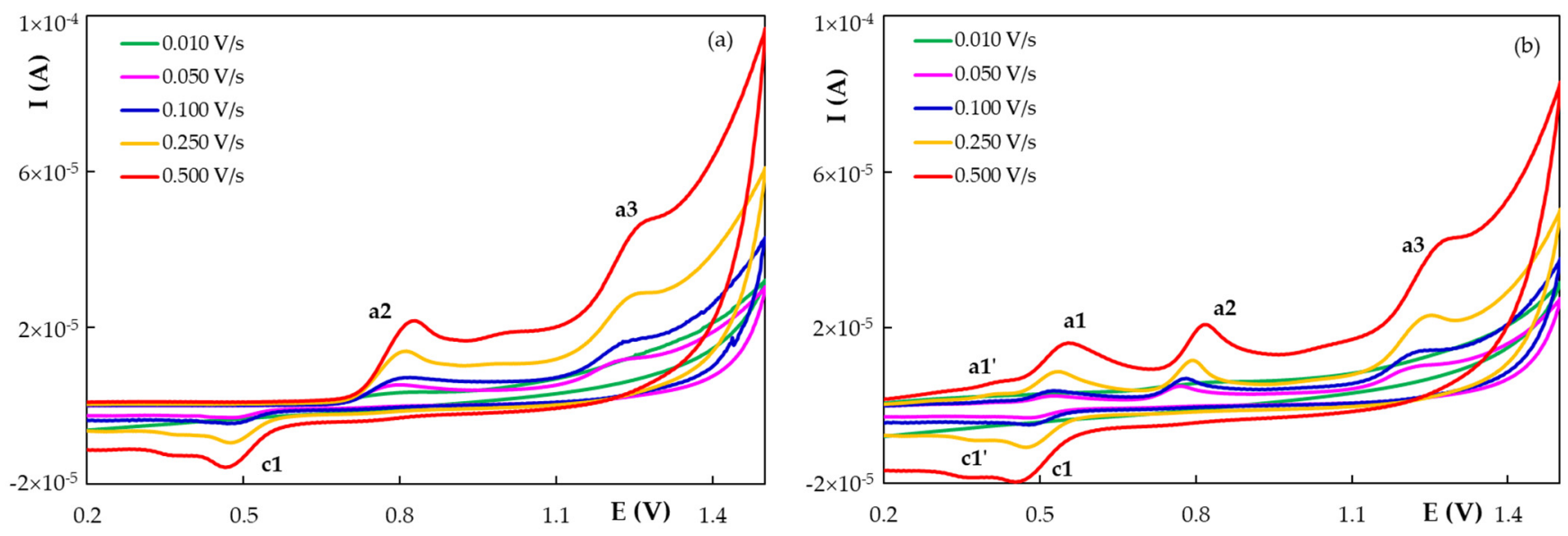

Figure 5. Selected cyclic voltammograms recorded with different scan rates at $\mathrm{H}$ type PGE for $1.00 \times 10^{-4} \mathrm{~mol} / \mathrm{L} \mathrm{HESP}$ in BRB solution $\mathrm{pH} 1.81$ (a) first potential scan and (b) second potential scan.

According to the different dependencies of their peak currents on the potential scan rate (Table 2), the first oxidation peak (a2) was governed by a diffusion controlled process whereas peak a3 was generated by a mainly adsorption controlled electrode process. In the backward scan of all voltammetric cycles, a single cathodic peak can be observed at $\sim 0.480 \mathrm{~V}$, corresponding to a quasi-reversible redox couple which, at scan rates higher than $0.025 \mathrm{~V} / \mathrm{s}$, generated in the positive-going direction of the second scan the anodic signal from $\sim 0.530 \mathrm{~V}$ (a1) (Figure $5 \mathrm{~b}$ ). Both peaks were due to mainly adsorption-controlled electrode processes.

Table 2. The data obtained from the cyclic voltammograms (Figure 5) recorded for HESP at H type PGE; peak current ( $\mathrm{I}_{\mathrm{p}}$, A) and potential scan rate ( $\mathrm{v}, \mathrm{V} / \mathrm{s})$.

\begin{tabular}{|c|c|c|c|}
\hline Peak & $I_{p}=f(v)$ & $I_{p}=f\left(v^{1 / 2}\right)$ & $\log I_{p}=f(\log v)$ \\
\hline \multicolumn{4}{|c|}{ First potential scan } \\
\hline $\mathrm{a} 2\left(\mathrm{E}_{\mathrm{pa} 2} \sim 0.800 \mathrm{~V}\right)$ & Non-linear & $\begin{array}{c}\mathrm{I}_{\mathrm{pa} 2}=2.00 \times 10^{-5} \mathrm{v}^{1 / 2}-5.00 \times 10^{-7} \\
\mathrm{R}^{2}=0.9893\end{array}$ & $\begin{array}{c}\log \mathrm{I}_{\mathrm{pa} 2}=0.6229 \log \mathrm{v}-4.6846 ; \\
\mathrm{R}^{2}=0.9660\end{array}$ \\
\hline $\mathrm{a} 3\left(\mathrm{E}_{\mathrm{pa} 3} \sim 1.230 \mathrm{~V}\right)$ & $\begin{array}{c}\mathrm{I}_{\mathrm{pa} 3}=1.00 \times 10^{-5} \mathrm{v}+7.00 \times 10^{-7} \\
\mathrm{R}^{2}=0.9895\end{array}$ & $\begin{array}{c}\mathrm{I}_{\mathrm{pa} 3}=1.00 \times 10^{-5} \mathrm{v}^{1 / 2}-2.00 \times 10^{-6} \\
\mathrm{R}^{2}=0.9611\end{array}$ & $\begin{array}{c}\log \mathrm{I}_{\mathrm{pa} 3}=1.0999 \log \mathrm{v}-4.7387 ; \\
\mathrm{R}^{2}=0.9841\end{array}$ \\
\hline $\mathrm{c} 1\left(\mathrm{E}_{\mathrm{pc} 1} \sim 0.480 \mathrm{~V}\right)$ & $\begin{array}{c}\mathrm{I}_{\mathrm{pc} 1}=-2.00 \times 10^{-5} \mathrm{v}-6.00 \times 10^{-7} ; \\
\mathrm{R}^{2}=0.9675\end{array}$ & $\begin{array}{c}\mathrm{I}_{\mathrm{pc} 1}=-1.00 \times 10^{-5} \mathrm{v}^{1 / 2}+2.00 \times 10^{-6} \\
\mathrm{R}^{2}=0.9893\end{array}$ & $\begin{array}{c}\log \mathrm{I}_{\mathrm{pc} 1}=0.8294 \log -4.8235 \\
\mathrm{R}^{2}=0.9927\end{array}$ \\
\hline
\end{tabular}


Table 2. Cont.

\begin{tabular}{|c|c|c|c|}
\hline Peak & $I_{p}=f(v)$ & $I_{p}=f\left(v^{1 / 2}\right)$ & $\log I_{p}=f(\log v)$ \\
\hline \multicolumn{4}{|c|}{ Second potential scan } \\
\hline $\mathrm{a} 1\left(\mathrm{E}_{\mathrm{pa} 1} \sim 0.530 \mathrm{~V}\right)$ & $\begin{array}{c}\mathrm{I}_{\mathrm{pa} 1}=2.00 \times 10^{-5} \mathrm{v}+4.00 \times 10^{-7} \\
\mathrm{R}^{2}=0.9904\end{array}$ & $\begin{array}{c}\mathrm{I}_{\mathrm{pa} 1}=2.00 \times 10^{-5} \mathrm{v}^{1 / 2}-2.00 \times 10^{-6} \\
\mathrm{R}^{2}=0.9913\end{array}$ & $\begin{array}{c}\log \mathrm{I}_{\mathrm{pa} 1}=0.9721 \log \mathrm{v}-4.7088 ; \\
\mathrm{R}^{2}=0.9647\end{array}$ \\
\hline $\mathrm{a} 2\left(\mathrm{E}_{\mathrm{pa} 2} \sim 0.800 \mathrm{~V}\right)$ & Non-linear & $\begin{array}{c}\mathrm{I}_{\mathrm{pa} 2}=2.00 \times 10^{-5} \mathrm{v}^{1 / 2}-8.00 \times 10^{-7} \\
\mathrm{R}^{2}=0.9931\end{array}$ & $\begin{array}{c}\log \mathrm{I}_{\mathrm{pa} 2}=0.6055 \log \mathrm{v}-4.7675 \\
\mathrm{R}^{2}=0.9860\end{array}$ \\
\hline $\mathrm{a} 3\left(\mathrm{E}_{\mathrm{pa} 3} \sim 1.230 \mathrm{~V}\right)$ & $\begin{array}{c}\mathrm{I}_{\mathrm{pa} 3}=2.00 \times 10^{-5} \mathrm{v}+4.00 \times 10^{-7} \\
\mathrm{R}^{2}=0.9889\end{array}$ & $\begin{array}{c}\mathrm{I}_{\mathrm{pa} 3}=2.00 \times 10^{-5} \mathrm{v}^{1 / 2}-2.00 \times 10^{-6} \\
\mathrm{R}^{2}=0.9824\end{array}$ & $\begin{array}{c}\log \mathrm{I}_{\mathrm{pa} 3}=0.8533 \log \mathrm{v}-4.4697 \\
\mathrm{R}^{2}=0.9833\end{array}$ \\
\hline $\mathrm{c} 1\left(\mathrm{E}_{\mathrm{pc} 1} \sim 0.480 \mathrm{~V}\right)$ & $\begin{array}{c}\mathrm{I}_{\mathrm{pc} 1}=-2.00 \times 10^{-5} \mathrm{v}-5.00 \times 10^{-7} \\
\mathrm{R}^{2}=0.9898\end{array}$ & $\begin{array}{c}\mathrm{I}_{\mathrm{pc} 1}=-2.00 \times 10^{-5} \mathrm{v}^{1 / 2}+2.00 \times 10^{-6} \\
\mathrm{R}^{2}=0.9935\end{array}$ & $\begin{array}{c}\log \mathrm{I}_{\mathrm{pc} 1}=0.9024 \log \mathrm{v}-4.6985 \\
\mathrm{R}^{2}=0.9934\end{array}$ \\
\hline
\end{tabular}

$\mathrm{I}_{\mathrm{pa} 1}, \mathrm{I}_{\mathrm{pa} 2}, \mathrm{I}_{\mathrm{pa} 3}, \mathrm{I}_{\mathrm{pc} 1}$, and $\mathrm{E}_{\mathrm{pa} 1}, \mathrm{E}_{\mathrm{pa} 2}, \mathrm{E}_{\mathrm{pa} 3}, \mathrm{E}_{\mathrm{pc} 1}$ : peak current and potential, respectively, for the signals a1, a2, a3, and c1 from Figure 6 .<smiles>[R6]c1cc(O)c2c(c1)O[C@H](c1ccc(OC)c(O)c1)CC2=O</smiles>

Figure 6. Proposed mechanism for HESP voltammetric behavior at H type PGE in BRB solution pH 1.81 [16,21].

As it can be observed from Figure 5, HESP main oxidation peak (a2) shifted towards more positive potentials with the scan rate increase, confirming once again the irreversibility of the process generating it. The a2 peak potential $\left(\mathrm{E}_{\mathrm{pa} 2}\right)$ dependencies on the logarithm of the potential scan rate were linear in both voltammetric cycles according to the regression equations $\mathrm{E}_{\mathrm{pa} 2, \text { scan } 1}=0.0506 \log \mathrm{v}+0.8536\left(\mathrm{R}^{2}=0.9922\right)$ and $\mathrm{E}_{\mathrm{pa2}, \text { scan } 2}=0.0481 \log \mathrm{v}+$ $0.8282\left(R^{2}=0.9881\right)$, respectively. Considering that for an irreversible electrode process the charge transfer coefficient $(\alpha)$ is 0.5 and comparing the slope values of these dependencies with the theoretical one of 2.303RT / $\alpha \mathrm{nF}$ from the Laviron equation [38], the number of exchanged electrons (n) was calculated to be 2.34 and 2.45, respectively, which can be approximated to $\mathrm{n}=2.00$. $\mathrm{R}, \mathrm{T}$, and $\mathrm{F}$ stand for the universal gas constant $(8.314 \mathrm{~J} / \mathrm{K} \times \mathrm{mol})$, the absolute temperature $(298.15 \mathrm{~K})$ and the Faraday constant $(96,480 \mathrm{C} / \mathrm{mol})$, respectively.

Despite the fact that it was beyond the aim of our study to establish an exact mechanism for HESP voltammetric behavior at $\mathrm{H}$ type PGE, correlating the cyclic voltammetric results with the data existing in the literature $[5,16,21,23,25]$, it was concluded that, also similar to diosmin [19], peak a2 was due to the irreversible oxidation of the guaiacol moiety $\left(3^{\prime}-\mathrm{OH}, 4^{\prime}-\mathrm{OCH}_{3}\right.$, the $o$-methoxyphenol group in ring B (Figure 1)) to o-benzoquinone. However, recent theoretical calculations regarding the relationship between the first anodic peak potential and the changes in the electronic structure of flavonoids pointed out that the electrochemical oxidation of these compounds, including HESP, start with the abstraction of an electron [39]. The cathodic peak (c1) was attributed to the quasi-reversible $\left(\mathrm{I}_{\mathrm{pa} 1} / \mathrm{I}_{\mathrm{pc} 1}>1.00\right)$ reduction of the $o$-benzoquinone moiety, previously generated in the 
forward scan, to the corresponding catechol (o-hydroxyphenol) group, which was further (re)oxidized in the second scan, indicated by peak a1. According to Kral and Sontag [16], $o$-quinone can add water generating a p-hydroxyphenol group (hydroquinone), which can be quasi-reversible oxidized. This process could be assigned to the bad defined redox couple peaks ( $\mathrm{a}^{\prime}$ and $\left.\mathrm{c1}^{\prime}\right)$ situated at the lowest positive potentials $\left(\mathrm{E}_{\mathrm{p}}<\sim 0.400 \mathrm{~V}\right)$ and observed at scan rates higher than $0.250 \mathrm{~V} / \mathrm{s}$. The anodic signal (a3) from more positive potentials $(\sim 1.230 \mathrm{~V})$ may be due to the irreversible oxidation of the 5-OH group from ring A [19], involving the transfer of one electron [21], but since the potential of this peak did not show a clear shift with the scan rate, the number of electrons transferred at $\mathrm{H}$ type PGE in $\mathrm{BRB}$ pH 1.81 could not be estimated in this step. The radical species generated during the electrode process corresponding to peak 3 could lead to polymerization processes [40], a fact that may explain the significant intensities decrease of the peaks $2 a$ and $3 a$ in the second scan (Figure 3), followed by their almost not observable decrease together with the slow increase of the redox peak pair (c1/a1) currents during the next scans, due to the electrode surface passivation by the formed polymers. No voltammetric signals were attributed to the glycosidic hydroxyl groups [23].

Considering all the above discussed results, a proposal of HESP possible electrode reactions pathways is presented in Figure 6. However, HESP has a complex electrochemical behavior at $\mathrm{H}$ type PGE in BRB pH 1.81 and more complementary studies are necessary to establish the exact mechanism for each of the cyclic voltammetric peaks presented by HESP.

\subsection{Hesperidine Voltammetric Quantification at the Pencil Graphite Electrode}

\subsubsection{Hesperidin Differential Pulse Voltammetric Determination at PGE}

It is well-known that DPV is a more sensitive technique than CV. Therefore, the influence of HESP concentration $\left(2.50 \times 10^{-8}\right.$ to $\left.5.00 \times 10^{-5} \mathrm{~mol} / \mathrm{L}\right)$ on both its main oxidation (a2) (Figure 7) and reduction (c1) signals, respectively, was investigated by recording DP voltammograms at $\mathrm{H}$ type PGE in BRB solution $\mathrm{pH} 1.81$ by scanning the potential in the anodic and cathodic direction, respectively. The intensity of the main anodic signal $\left(\mathrm{I}_{\mathrm{pa} 2}\right)$ varied linearly with the concentration over two orders of magnitude (Figure 7, Table 3). The cathodic DPV peak current $\left(\mathrm{I}_{\mathrm{pc} 1}\right)$ presented a linear dependence on the analyte concentration $\left(\mathrm{I}_{\mathrm{pc} 1, \mathrm{DPV}}=1.7632 \times \mathrm{C}_{\mathrm{HESP}}-4.00 \times 10^{-8} ; \mathrm{R}^{2}=0.9985\right)$ only within a narrow range, namely $2.00 \times 10^{-6}-1.20 \times 10^{-5} \mathrm{~mol} / \mathrm{L}$ HESP (Table 3 ).
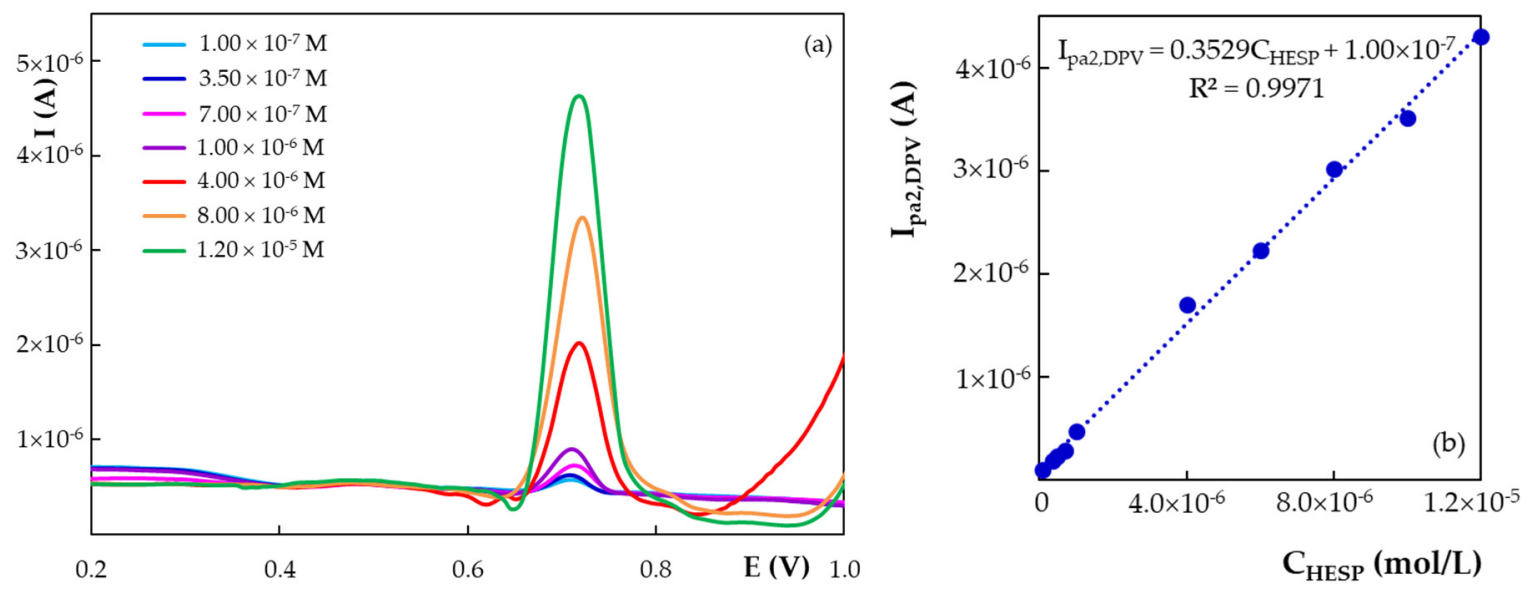

Figure 7. Selected differential pulse voltammograms recorded in the anodic direction at $\mathrm{H}$ type PGE for different concentrations of HESP in BRB solution pH 1.81 and the corresponding calibration graph (inset). (a) Selected differential pulse voltammograms recorded (b) the corresponding calibration graph. 
Table 3. The performance characteristics of voltammetric methods reported in the literature for hesperidin determination.

\begin{tabular}{|c|c|c|c|c|c|}
\hline Technique & Electrode & Linear Range (mol/L) & $\begin{array}{l}\text { Limit of Detection } \\
(\mathrm{mol} / \mathrm{L})\end{array}$ & Sample & Ref. \\
\hline $\begin{array}{c}\text { DPV } \\
\text { DPAdSV }\end{array}$ & PGE & $\begin{array}{l}1.00 \times 10^{-7}-1.20 \times 10^{-5} \\
5.00 \times 10^{-8}-1.00 \times 10^{-6}\end{array}$ & $\begin{array}{l}8.58 \times 10^{-8} \\
1.90 \times 10^{-8}\end{array}$ & Dietary supplements & This work \\
\hline CSV & HMDE & $1.64 \times 10^{-7}-4.10 \times 10^{-5}$ & $1.37 \times 10^{-7}$ & $\begin{array}{l}\text { Orange juice, phy- } \\
\text { topharmaceuticals }\end{array}$ & {$[34]$} \\
\hline LSAdSV & HMDE & $5.00 \times 10^{-7}-8.00 \times 10^{-6}$ & $3.00 \times 10^{-7}$ & & {$[41]$} \\
\hline SWCAdSV & $\begin{array}{c}\text { HMDE } \\
\text { HMDE } / \mathrm{Cu}^{2+}\end{array}$ & $\begin{array}{l}1.90 \times 10^{-8}-6.54 \times 10^{-7} \\
7.40 \times 10^{-7}-2.85 \times 10^{-6} \\
9.09 \times 10^{-7}-2.85 \times 10^{-6} \\
9.00 \times 10^{-9}-1.84 \times 10^{-7}\end{array}$ & $\begin{array}{l}7.54 \times 10^{-9} \\
5.76 \times 10^{-8} \\
7.58 \times 10^{-8} \\
4.89 \times 10^{-9}\end{array}$ & $\begin{array}{l}\text { Bulk } \\
\text { Urine } \\
\text { Serum } \\
\text { Bulk }\end{array}$ & {$[42]$} \\
\hline SWAdSV & BDDE & $4.09 \times 10^{-6}-1.15 \times 10^{-4}$ & $1.20 \times 10^{-6}$ & Dietary supplements & {$[5]$} \\
\hline $\mathrm{AD}$ & ITO-EMC & $3.00-45.00 \mu \mathrm{g} / \mathrm{mL}$ & $0.57 \mu \mathrm{g} / \mathrm{mL}$ & $\begin{array}{l}\text { Pericarpium Citri } \\
\text { reticulatae } \\
\text { pericarpium }\end{array}$ & {$[43]$} \\
\hline $\mathrm{AD}$ & CNT-PR & $1.00 \times 10^{-6}-1.00 \times 10^{-3}$ & $2.30 \times 10^{-7}$ & $\begin{array}{l}\text { Pericarpium Citri } \\
\text { reticulatae }\end{array}$ & [22] \\
\hline $\mathrm{AD}$ & $\mathrm{AuNPs} / \mathrm{rGO} / \mathrm{GCE}$ & $5.00 \times 10^{-8}-8.00 \times 10^{-6}$ & $8.20 \times 10^{-9}$ & $\begin{array}{l}\text { Pericarpium Citri } \\
\text { reticulatae, } \text { Chinese } \\
\text { medicines }\end{array}$ & {$[26]$} \\
\hline DPAdSV & $\mathrm{SnO}_{2}-\mathrm{CPB} / \mathrm{GCE}$ & $1.00 \times 10^{-7}-7.50 \times 10^{-5}$ & $7.70 \times 10^{-8}$ & Orange juice & {$[30]$} \\
\hline DPAdSV & $\mathrm{SiO}_{2}-\mathrm{CPE}$ & $5.00 \times 10^{-7}-2.50 \times 10^{-5}$ & $2.50 \times 10^{-7}$ & Chinese medicines & {$[32]$} \\
\hline SWAdSV & MWCNT-BPPGE & $2.00 \times 10^{-8}-3.00 \times 10^{-5}$ & $7.30 \times 10^{-9}$ & Orange juice & [23] \\
\hline DPV & nGp-Bg/MCPE & $1.00 \times 10^{-7}-1.00 \times 10^{-4}$ & $5.00 \times 10^{-8}$ & $\begin{array}{l}\text { Lemon juice, orange } \\
\text { rind, peppermint } \\
\text { extract }\end{array}$ & [25] \\
\hline DPV & Polyaluminon/f-SWCNT/GCE & $1.00 \times 10^{-7}-2.50 \times 10^{-5}$ & $2.90 \times 10^{-8}$ & $\begin{array}{l}\text { Orange and } \\
\text { grapefruit juice }\end{array}$ & [24] \\
\hline DPV & PAP-MIP/AuNPs/uaC/GCE & $8.00 \times 10^{-8}-3.00 \times 10^{-5}$ & $4.50 \times 10^{-8}$ & Chinese medicines & [31] \\
\hline DPV & ERGO/P(PDCA)/dsDNA/GCE & $8.20 \times 10^{-7}-8.20 \times 10^{-5}$ & $2.40 \times 10^{-7}$ & Serum & [27] \\
\hline DPV & ePGE & $5.00 \times 10^{-7}-1.00 \times 10^{-5}$ & $2.00 \times 10^{-7}$ & Pharmaceuticals & [21] \\
\hline
\end{tabular}

DPV: differential pulse voltammetry; DPAdSV: differential pulse adsorptive stripping voltammetry; PGE: pencil graphite electrode; CSV: cathodic stripping voltammetry; HMDE: hanging mercury drop electrode; LSAdSV: linear sweep adsorptive stripping voltammetry; SWCAdSV: square wave cathodic adsorptive stripping voltammetry; SWAdSV: square wave adsorptive stripping voltammetry; BDDE: boron doped diamond electrode; AD: amperometric detection; ITO-MEC: indium tin oxide on electrophoretic microchip; CNT-PR: carbon nanotube-phenolic resin; AuNPs/rGO/GCE: gold nanoparticles and reduced graphene oxide modified glassy carbon electrode; $\mathrm{SnO}_{2}$-CPB/GCE: tin oxide/cetylpyridinium bromide modified glassy carbon electrode; $\mathrm{SiO}_{2}-\mathrm{CPE}$ : $\mathrm{SiO}_{2}$-modified carbon paste electrode; MWCNT-BPPGE: multiwalled carbon nanotubes modified basal-plane pyrolytic graphite electrode; $\mathrm{nGp}-\mathrm{Bg} / \mathrm{MCPE}$ : nano-graphene platelets/Brilliant green modified carbon paste electrode; Polyaluminon/f-SWCNT/GCE: polyaluminon/functionalized-single-walled carbon nanotubes modified glassy carbon electrode; PAP-MIP/AuNPs/uaC/GCE: poly-o-aminothiophenol based molecularly imprinted polymer/gold nanoparticles/ultrafine activated carbon modified glassy carbon electrode; ERGO/P(PDCA)/dsDNA/GCE: reduced graphene oxide/poly(2,6-pyridinedicarboxylic acid)/double stranded DNA modified glassy carbon electrode; ePGE: electroactivated pencil graphite electrode.

\subsubsection{Adsorptive Differential Pulse Voltammetric Determination}

In order to extend the linear ranges towards lower concentrations, the adsorptive properties of HESP and its oxidation products were tested on the a2 and c1 DP voltammetric peaks, respectively. The corresponding signals were obtained after enabling the analyte or its oxidation products deposition at $\mathrm{H}$ type PGE by applying different accumulation times $\left(\mathrm{t}_{\mathrm{acc}}\right)$ and potentials $\left(\mathrm{E}_{\mathrm{acc}}\right)$, for $1.00 \times 10^{-6} \mathrm{~mol} / \mathrm{L}$ HESP in BRB $\mathrm{pH} 1.81$ solution. The DP voltammograms recorded in the anodic direction after keeping the electrode at accumulation potentials between -0.100 and $0.200 \mathrm{~V}$ and for different accumulation times up to $45 \mathrm{~s}$ did not emphasize an enhancement of the a2 peak current, suggesting that HESP was not adsorbed at the electrode surface. This observation can be correlated with the diffusion controlled nature of this signal, as it was previously concluded after CV studies (Table 2). 
The reduction peak (c1) was due to the adsorptive (Table 2) reduction of the $o$ benzoquinone moiety formed during the oxidation of the $o$-methoxyphenol group in ring $\mathrm{B}$, corresponding in the cyclic voltammograms (Figure 5) to peak a2 situated between 0.700 and $0.800 \mathrm{~V}$. Consequently, the influence of $\mathrm{E}_{\mathrm{acc}}$ on the reduction peak (c1) was examined at anodic potentials between 0.800 and $1.200 \mathrm{~V}$, the highest signal being obtained for $E_{\text {acc }}=1.000 \mathrm{~V}$. The effect of the accumulation time was investigated by keeping the $\mathrm{H}$ type PGE at $1.000 \mathrm{~V}$ for periods up to $110 \mathrm{~s}$. The most intense signal was recorded for $60 \mathrm{~s}$. At longer deposition periods, the peak current decreased slightly due to the electrode surface saturation with the hesperidin $o$-quinone derivative. The accumulation step was performed under constant stirring of the analyzed solution, whereas the voltammograms were recorded in quiet solutions, subsequently, a $10 \mathrm{~s}$ equilibration time. By applying the differential pulse adsorptive voltammetric technique (DPAdSV) using the optimized conditions $\left(\mathrm{E}_{\mathrm{acc}}=1.000 \mathrm{~V}\right.$ and $\left.\mathrm{t}_{\mathrm{acc}}=60 \mathrm{~s}\right)$, the reduction peak current increased with HESP concentration according to the regression equation $\mathrm{I}_{\mathrm{pc} 1 \text {, DPAdsV }}=45.055 \times \mathrm{C}_{\mathrm{HESP}}-5.00 \times$ $10^{-7}\left(R^{2}=0.9945\right)$. At concentrations above $1.00 \times 10^{-6} \mathrm{~mol} / \mathrm{L}$ HESP (Table 3$)$, the further peak current enhancement was insignificant due to the saturation of the electrode surface with the electroactive species.

The limits of detection (LoD) and quantification (LoQ) were estimated for the two more sensitive methods (DPV on the oxidation signal a2 and DPAdSV on the reduction signal c1) applying the relations $\operatorname{LoD}=3.3 \mathrm{~s}_{\mathrm{x} / \mathrm{y}} / \mathrm{b}$ and $\mathrm{LoQ}=10.0 \mathrm{~s}_{\mathrm{x} / \mathrm{y}} / \mathrm{b}$, where $\mathrm{s}_{\mathrm{x} / \mathrm{y}}$ stands for the residual standard deviation and $\mathrm{b}$ for the slope of the calibration curve [44]. The LoDs of the two developed methods are given in Table 4, whereas the LoQs were $2.60 \times 10^{-7}$ and $5.75 \times 10^{-8} \mathrm{~mol} / \mathrm{L}$ HESP for DPV oxidation $_{\text {and }}$ DPAdSV $V_{\text {reduction, }}$ respectively.

Table 4. Results obtained in precision study for the voltammetric determination of different concentration levels of HESP in BRB pH 1.81 solutions at $\mathrm{H}$ type PGE.

\begin{tabular}{ccccccc}
\hline Technique & \multicolumn{3}{c}{ DPV (Oxidation) } & \multicolumn{3}{c}{ DPAdSV (Reduction) } \\
\hline $\begin{array}{c}\text { Concentration } \\
(\mathbf{m o l} / \mathrm{L})\end{array}$ & $\mathbf{1 . 0 0} \times \mathbf{1 0}^{-\mathbf{7}}$ & $\mathbf{1 . 0 0} \times \mathbf{1 0}^{-\mathbf{6}}$ & $\mathbf{1 . 0 0} \times \mathbf{1 0}^{-\mathbf{5}}$ & $\mathbf{5 . 0 0} \times \mathbf{1 0}^{-\mathbf{8}}$ & $\mathbf{3 . 0 0} \times \mathbf{1 0}^{-\mathbf{7}}$ & $\mathbf{1 . 0 0} \times \mathbf{1 0}^{-\mathbf{6}}$ \\
\hline $\mathrm{RSD} \%$ intra-day & 8.17 & 5.99 & 2.50 & 8.94 & 5.70 & 3.13 \\
\hline $\mathrm{RSD} \%$ inter-day & 8.55 & 6.41 & 3.27 & 9.38 & 6.01 & 3.36 \\
\hline
\end{tabular}

\subsection{Precision of HESP Voltammetric Response at the Pencil Graphite Electrode}

The precision of HESP voltammetric response at $\mathrm{H}$ type PGE, expressed as percentage relative standard deviation (RSD\%), was evaluated at three levels of concentrations, corresponding to the lower and upper limit of the linear ranges and also at an intermediate concentration (Table 4). Six replicate measurements for each concentration were always performed at a new pencil lead during one day (intra-day assay-repeatability) and during six successive days (inter-day assay-intermediate precision), respectively. The RSD $\%$ values were situated within the accepted limits for the corresponding concentration levels [45], indicating a good precision of the developed method.

\subsection{Interference Studies}

Polyphenols' antioxidant properties and their voltammetric analysis is mainly based on the oxidation of the different phenyl/hydroxyl groups existing in their molecular structure. The species belonging to the same class of chemical compounds have very similar structures, and as a result, the selective determination of one in the presence of the others is most often quite difficult. However, voltammetric methods allow the selective analysis of different classes of antioxidants based on their oxidation potential. For example, in acidic media, hesperidin and its structurally related flavones naringenin [20], and diosmin [19] presented at PGE the main anodic signal at around $0.700-0.800 \mathrm{~V}$ so that they can be differentiated from hydroxycinnamic acids [33] which showed the oxidation 
peak at about 0.550 V. Based on Blasco et al. [46] "electrochemical index", this behavior suggests that they possess a higher antioxidant effectiveness in comparison to the flavones.

The selectivity of the developed DPV at $\mathrm{H}$ type PGE method for HESP quantification in $\mathrm{BRB} \mathrm{pH} 1.81$ was tested by recording in the same conditions the DP voltammograms for the structurally related glycosylated bioflavonoids diosmin (DIO) and naringin (NG) and of the hydroxybenzoic acid, gallic acid (GA), a naturally occurring polyphenolic acid found in various fruits, plants, and medicinal herbs, which is most commonly used as reference for the determination of total phenolic content (Figure 8). It can be observed that GA and NG main oxidation peaks are situated with about $0.200 \mathrm{~V}$ before and after the HESP a2 signal, respectively. Thus, NG did not affect HESP quantification, whereas at a tenfold excess of GA, its second oxidation peak may produce a slight interference in HESP assay. DIO oxidation signal overlapped with HESP main anodic peak a2 used for its quantitative determination and thus, these two analytes cannot be detected simultaneously in a mixture. However, this result was predictable given that the molecular structures of the two compounds differ by the presence of a double bond in the benzopyran nucleus of DIO molecule.

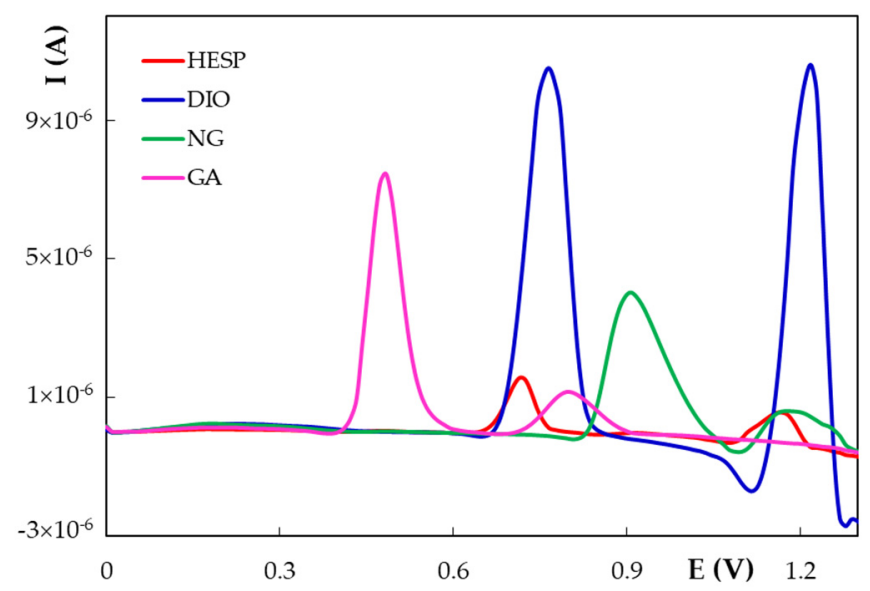

Figure 8. Overlaid differential pulse voltammograms recorded in the anodic direction at $\mathrm{H}$ type PGE for $5.00 \times 10^{-6} \mathrm{~mol} / \mathrm{L} \mathrm{HESP}, 1.00 \times 10^{-5} \mathrm{~mol} / \mathrm{L} \mathrm{DIO}, 5.00 \times 10^{-5} \mathrm{~mol} / \mathrm{L} \mathrm{NG}$, and $5.00 \times 10^{-5} \mathrm{~mol} / \mathrm{L} \mathrm{GA}$.

The discrimination between the voltammetric signals of HESP and DIO by electrode surface modification will be the aim of another study. Having in mind that the structure of the two analytes differ by only a double bond in ring $\mathrm{C}$, a molecularly imprinted polymer will probably not help in this respect, but the modification with proper nanomaterials may result in different electrocatalytic activity on the two bioflavonoids. However, a better selectivity realized by the electrode modification, will involve supplementary steps, longer analysis times and a higher reagents consumption.

\subsection{Recovery Studies and Analytical Applications}

As far as we know, HESP does not exist as the only bioflavonoid in pharmaceutical preparations or in dietary supplements and even more so in plants or fruits (mainly citrus) and products derived from them. Therefore, the applicability of the developed DPV method at $\mathrm{H}$ type PGE was tested by the assessment of the bioflavonoids contents in the dietary supplement Good Routine C-Your-Immunity. This product was selected for the analysis because each capsule contains in addition to $10.00 \mathrm{mg}$ citrus bioflavonoids (from Citrus Sinensis fruits) with 60\% hesperidin, vitamin C (ascorbic acid, AA), and the flavanol quercetin (QT), antioxidants belonging to different classes of compounds. From the two previously discussed differential pulse voltammetric methods, one without the accumulation step, namely DPV, was employed for the assessment of the bioflavonoid content of the dietary supplement capsules, expressed as mg hesperidin, due to the fact that: (i) it presented a linear range of two orders of magnitude; (ii) it is less time consuming 
than the DPAdSV method and (iii) its lower limit of the linear range and LoD were sufficient for the analysis of pharmaceuticals and dietary supplements with known analyte content. Moreover, the concentration of target species in the working sample solution can be adjusted by taking for the analysis a proper amount of the considered product. The working solutions of dietary supplement capsules were prepared and analyzed simply and rapidly as described in Section 2.3. Procedures. Six replicate samples were measured. The DP voltammograms recorded for these solutions showed two well-defined oxidation signals, a higher one at potentials around $0.500 \mathrm{~V}$ and a less intense one at about $0.710 \mathrm{~V}$, respectively (Figure 9). It is known that AA [47] and QT [48] are oxidized at lower potentials, having thus a higher antioxidant efficiency than HESP [46]. Therefore, considering the peak heights and potentials it may be assumed that the signal situated at less positive potentials was due to the QT + AA and the more anodic one to the HESP electrooxidation, respectively. This conclusion was supported by the fact that the intensity of the more positive and initially higher signal remained unaffected, whereas the anodic peak from approximately $0.710 \mathrm{~V}$ increased linearly upon addition of HESP stock solution enabling thus the quantitative determination of the flavone by using the standard addition method. The bioflavonoid content of the dietary supplement, expressed as mg HESP equivalent, and the corresponding percentage recovery (\%R) (Table 5) were estimated using the currents measured for HESP main oxidation peaks recorded before and after each of the three additions of small volumes of HESP stock solution and considering all dilutions carried out during the sample preparation steps.
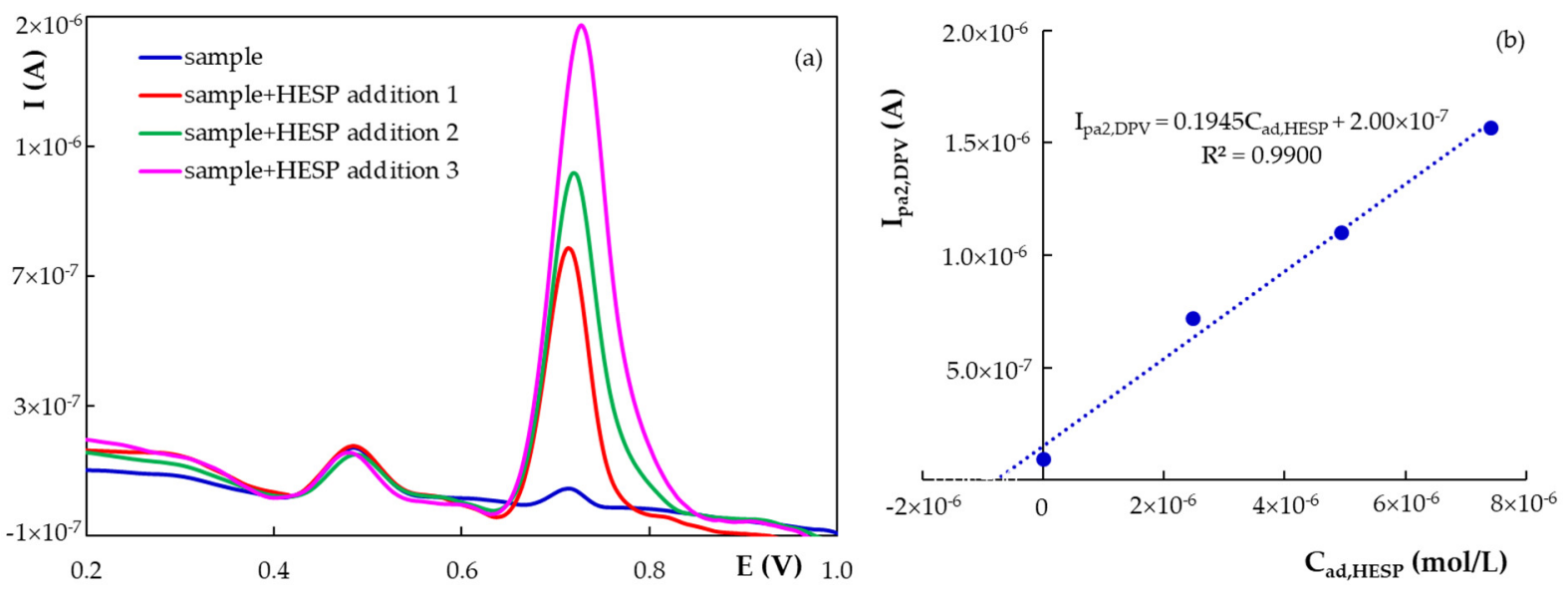

Figure 9. Differential pulse voltammograms recorded at $\mathrm{H}$ type PGE for $10 \mathrm{~mL}$ diluted dietary supplement capsules solution in BRB pH 1.81 before and after successive additions of $0.025 \mathrm{~mL} 4.00 \times 10^{-4} \mathrm{~mol} / \mathrm{L}$ HESP stock solution and the corresponding calibration graph (inset). (a) Differential pulse voltammograms recorded (b) the corresponding calibration graph.

Table 5. The results obtained for the DPV at H type PGE assessment of the bioflavonoids content, expressed as mg HESP, from Good Routine C-Your-Immunity dietary supplement capsules.

\begin{tabular}{cc}
\hline Claimed bioflavonoids content $(\mathrm{mg})$ & 10 \\
\hline Found by DPV \pm SD (mg HESP) & $10.36 \pm 0.46$ \\
\hline RSD, $\%$ & 4.63 \\
\hline Average $\% \mathrm{R} \pm \mathrm{SD}$ & $103.58 \pm 4.63$ \\
\hline Relative error (er\%) & 3.60 \\
\hline SD: standard deviation; RSD: relative standard deviation; \%R: percentage recovery.
\end{tabular}

The results pointed out that there was only a small difference between the bioflavonoids content, expressed as mg HESP equivalent, of the analyzed complex dietary supplement obtained by the developed voltammetric method and that claimed by the manufacturer, 
the percentage recovery being near to $100 \%$ (Table 5. The results highlighted that the developed DPV at $\mathrm{H}$ type PGE method distinguishes species with different antioxidant effectiveness (i.e., AA and QT vs. bioflavonoids containing mainly HESP), but it is not selective enough to permit the quantification of HESP in the presence of other structurally related compounds.

\section{Conclusions}

The present paper discusses the electrochemical behavior of HESP at a cheap, disposable, bare, non-activated PGE. HESP cyclic voltammograms are similar to those obtained in similar conditions (PGE in acidic medium) for structurally related species (diosmin [19], naringenin [20]) and the results also correlated well with the data previously reported for HESP oxidation at various other working electrodes. By selecting the proper working conditions (main oxidation signal, DPV, H type PGE, BRB pH 1.81), HESP could be quantified over two orders of magnitude with a LoD of $8.58 \times 10^{-8} \mathrm{~mol} / \mathrm{L} \mathrm{HESP}$, which could be lowered to $1.90 \times 10^{-8} \mathrm{~mol} / \mathrm{L}$ HESP by applying adsorptive stripping voltammetry on the reduction signal. From the only 14 reports related to HESP, voltammetric determination found in the literature and presented in Table 3, only four of them used un-modified/untreated working electrodes, namely HMDE [34,41,42] and BDDE [5], none of them being a carbon-based electrode. Despite the fact that modified working electrodes were employed, half of the 14 reported methods have higher LODs as that obtained without accumulation (DPV) in our study. Considering AdSDPV, only three published data [23,26,42] indicated lower LODs as those obtained in the current work at the unmodified PGE. The developed DPV at $H$ type PGE method distinguishes species with different antioxidant effectiveness (i.e., AA and QT vs. bioflavonoids containing mainly HESP), but it is not selective enough to permit the quantification of HESP in the presence of other structurally related compounds. However, it was successfully applied to the simple and rapid assessment of the bioflavonoids content, expressed as mg HESP equivalent, of a complex dietary supplement. The improvement of the selectivity and sensitivity could be achieved by the development of a PGE modified with proper nanomaterials, but this is the scope of a future research study.

The relative wide linear range and the limits of detection and quantification of the voltammetric methods described in this paper are satisfactory for HESP determin ation $[5,21,24,27,32,34,41]$ in dietary and medicinal products. Moreover, they are easy, rapid, and cost-effective, employing a non-modified, disposable, commonly available, ecoand user-friendly pencil graphite electrode. Having in mind the continuous development of more and more various new dietary and medicinal products based on bioflavonoids, we consider that the development of simple, cheap, and fast screening methods is of major interest in the products quality control and our research pointed out that DPV at PGE is a suitable alternative to fulfill this scope.

Supplementary Materials: The following are available online at https: / www.mdpi.com/article / 10.3390 / chemosensors9110323/s1, Figure S1: Differential pulse voltammetric peak $\left(\mathrm{E}_{\mathrm{pa} 2} \sim 0.710 \mathrm{~V}\right)$ currents recorded at $\mathrm{H}$ type PGE for $1.00 \times 10^{-5} \mathrm{M}$ HESP in BRB solution $\mathrm{pH} 1.81$ (a) prepared on different days from the same stock solution $\left(1.00 \times 10^{-3} \mathrm{~mol} / \mathrm{L} \mathrm{HESP}\right.$ in $\left.0.05 \mathrm{~mol} / \mathrm{L} \mathrm{NaOH}\right)$ stored in different conditions and (b) kept in the voltammetric cell for $100 \mathrm{~min}$., Table S1: The main oxidation peak (a2) currents obtained by DPV for $4.00 \times 10^{-6} \mathrm{M}$ HESP in BRB solution $\mathrm{pH} 1.81$ at $\mathrm{H}$ type PGE electroactivated in different conditions.

Author Contributions: Conceptualization, I.G.D. and S.C.L.; Methodology, I.G.D.; Validation, M.B. and D.-E.P.; Formal analysis, I.G.D., D.-E.P. and M.B.; Investigation, I.G.D. and N.N.; Data curation, I.G.D., N.N., S.R. and A.M.C.; Writing-original draft preparation, I.G.D. and N.N.; Writing—review and editing, M.B. and D.-E.P.; Supervision, S.C.L., S.R. and A.M.C. All authors have read and agreed to the published version of the manuscript.

Funding: This research received no external funding.

Institutional Review Board Statement: Not applicable. 
Informed Consent Statement: Not applicable.

Conflicts of Interest: The authors declare no conflict of interest.

\section{References}

1. Li, C.; Schluesener, H. Health-promoting effects of the citrus flavanone hesperidin. Crit. Rev. Food Sci. Nutr. 2017, 57, 613-631. [CrossRef] [PubMed]

2. Bellavite, P.; Donzelli, A. Hesperidin and SARS-CoV-2: New light on the healthy function of citrus fruits. Antioxidants 2020, 9, 742. [CrossRef] [PubMed]

3. Hajialyani, M.; Hosein Farzaei, M.; Echeverría, J.; Nabavi, S.M.; Uriarte, E.; Sobarzo-Sánchez, E. Hesperidin as a neuroprotective agent: A review of animal and clinical evidence. Molecules 2019, 24, 648. [CrossRef] [PubMed]

4. Sun, K.; Xiang, L.; Ishihara, S.; Matsuura, A.; Sakagami, Y.; Qi, J. Anti-aging effects of hesperidin on Saccharomyces cerevisiae via inhibition of reactive oxygen species and UTH1 gene expression. Biosci. Biotechnol. Biochem. 2012, 76, 640-645. [CrossRef] [PubMed]

5. Yiğit, A.; Yardım, Y.; Şentürk, Z. Square-wave adsorptive stripping voltammetric determination of hesperidin using a boron-doped diamond electrode. J. Anal. Chem. 2020, 75, 656-661. [CrossRef]

6. Mas-Capdevila, A.; Teichenne, J.; Domenech-Coca, C.; Caimari, A.; Del Bas, J.M.; Escoté, X.; Crescenti, A. Effect of hesperidin on cardiovascular disease risk factors: The role of intestinal microbiota on hesperidin bioavailability. Nutrients 2020, 12, 1488. [CrossRef]

7. Pandey, P.; Khan, F. A mechanistic review of the anticancer potential of hesperidin, a natural flavonoid from citrus fruits. Nutr. Res. 2021, 92, 21-31. [CrossRef]

8. Xiong, H.; Wang, J.; Ran, Q.; Lou, G.; Peng, C.; Gan, Q.; Hu, J.; Sun, J.; Yao, R.; Huang, Q. Hesperidin: A therapeutic agent for obesity. Drug Des. Dev. Ther. 2019, 13, 3855-3866. [CrossRef]

9. Matos, A.L.; Bruno, D.F.; Ambrósio, A.F.; Santos, P.F. The benefits of flavonoids in diabetic retinopathy. Nutrients 2020, $12,3169$. [CrossRef]

10. Xie, L.; Gu, Z.; Liu, H.; Jia, B.; Wang, Y.; Cao, M.; Song, R.; Zhang, Z.; Bian, Y. The anti-depressive effects of hesperidin and the relative mechanisms based on the NLRP3 inflammatory signaling pathway. Front. Pharmacol. 2020, 11, 1251. [CrossRef]

11. Kim, J.; Wie, M.-B.; Ahn, M.; Tanaka, A.; Matsuda, H.; Shin, T. Benefits of hesperidin in central nervous system disorders: A review. Anat. Cell Biol. 2019, 52, 369-377. [CrossRef]

12. Kotru, S.; Klimuntowski, M.; Ridha, H.; Uddin, Z.; Askhar, A.A.; Singh, G.; Howlader, M.M.R. Electrochemical sensing: A prognostic tool in the fight against COVID-19. Trends Anal. Chem. 2021, 136, 116198. [CrossRef]

13. Suleman, S.; Shukla, S.K.; Malhotra, N.; Bukkitgar, S.D.; Shetti, N.P.; Pilloton, R.; Narang, J.; Tan, Y.N.; Aminabhavi, T.M. Point of care detection of COVID-19: Advancement in biosensing and diagnostic methods. Chem. Eng. J. 2021, 414, 128759. [CrossRef] [PubMed]

14. Zheng, G.D.; Yang, X.J.; Chen, B.Z.; Chao, Y.X.; Hu, P.J.; Cai, Y.; Wu, B.; Wei, M.Y. Identification and determination of chemical constituents of Citrus reticulata semen through ultra high performance liquid chromatography combined with $Q$ Exactive Orbitrap tandem mass spectrometry. J. Sep. Sci. 2020, 43, 438-451. [CrossRef] [PubMed]

15. Baira, E.; Dagla, I.; Siapi, E.; Zoumpoulakis, P.; Tsarbopoulos, A.; Simitzis, P.; Goliomytis, M.; Deligeorgis, S.G.; Skaltsounis, A.-L.; Gikas, E. Development and validation of a UPLC-ESI (-)-MS/MS methodology for the simultaneous quantification of hesperidin, naringin, and their aglycones in chicken tissue samples. J. AOAC Int. 2020, 103, 83-88. [CrossRef] [PubMed]

16. Kral, K.; Sontag, G. Elektrochemische Oxydation von Flavonoiden an einer glasartigen Kohlenstoffelektrode. Mikrochim. Acta 1982, 78, 29-41. [CrossRef]

17. Temerk, Y.M.; Ibrahim, M.S.; Kotb, M.; Schuhmann, W. Renewable pencil electrodes for highly sensitive anodic stripping voltammetric determination of 3-hydroxyflavone and morin in bulk form and in biological fluids. Electroanalysis 2013, 25, 1381-1387. [CrossRef]

18. Temerk, Y.M.; Ibrahim, M.S.; Schuhmann, W. Simultaneous anodic adsorptive stripping voltammetric determination of luteolin and 3-hydroxyflavone in biological fluids using renbewable pencil graphite electrode. Electroanalysis 2019, 31, 1095-1103. [CrossRef]

19. David, I.G.; Oancea, A.G.; Buleandra, M.; Popa, D.E.; Iorgulescu, E.E.; Ciobanu, A.M. Disposable pencil graphite electrode for diosmin voltammetric analysis. Micromachines 2021, 12, 351. [CrossRef]

20. David, I.G.; Litescu, S.C.; Popa, D.E.; Buleandra, M.; Iordache, L.; Albu, C.; Alecu, A.; Penu, R.L. Voltammetric analysis of naringenin at a disposable pencil graphite electrode-Application to polyphenol content determination in citrus juice. Anal. Methods 2018, 10, 5763-5772. [CrossRef]

21. Šafranko, S.; Stanković, A.; Asserghine, A.; Jakovljević, M.; Hajra, S.; Nundy, S.; Medvidović-Kosanović, M.; Jokić, S. Electroactivated disposable pencil graphite electrode-New, cost-effective, and sensitive electrochemical detection of bioflavonoid hesperidin. Electroanalysis 2020, 33, 1063-1071. [CrossRef]

22. Wang, W.; Wang, J.; Zhang, L.; Chen, G. Carbon nanotube-phenolic resin composite electrode fabricated by far Infrared-assisted crosslinking for enhanced amperometric detection. Electroanalysis 2019, 31, 756-765. [CrossRef]

23. Sims, M.J.; Li, Q.; Kachoosangi, R.T.; Wildgoose, G.G.; Compton, R.G. Using multiwalled carbon nanotube modified electrodes for the adsorptive striping voltammetric determination of hesperidin. Electrochim. Acta 2009, 54, 5030-5034. [CrossRef] 
24. Zhupanova, A.; Guss, E.; Ziyatdinova, G.; Budnikov, H. Simultaneous voltammetric determination of flavanones using an electrode based on functionalized single-walled carbon nanotubes and polyaluminon. Anal. Lett. 2020, 53, 2170-2189. [CrossRef]

25. Manasa, G.; Mascarenhas, R.J.; Bhakta, A.K.; Mekhalif, Z. Nano-graphene-platelet/Brilliant-green composite coated carbon paste electrode interface for electrocatalytic oxidation of flavanone Hesperidin. Microchem. J. 2021, 160, 105768. [CrossRef]

26. Gao, Y.; Wu, X.; Wang, H.; Lu, W.; Guo, M. Highly sensitive detection of hesperidin using AuNPs/rGO modified glassy electrode. Analyst 2018, 143, 297-303. [CrossRef]

27. Tı̆̆ , G.A.; Bolat, E.Ö.; Zeybek, B.; Pekyardımcı, Ş. Hesperidin-dsDNA interaction based on electrochemically reduced graphene oxide and poly-(2,6-pyridinedicarboxylic acid) modified glassy carbon electrode. Hacettepe J. Biol. Chem. 2016, 44, 487-497. [CrossRef]

28. Hu, J.; Zhou, R.; Lin, H.; Wei, Q.; Hu, F.; Yang, X. Novel plant flavonoid electrochemical sensor based on in-situ and controllable double-layered membranes modified electrode. PLOS ONE 2020, 15, e0237583. [CrossRef]

29. Hu, J.; Zhang, Z. Application of electrochemical sensors based on carbon nanomaterials for detection of flavonoids. Nanomaterials 2020, 10, 2020. [CrossRef]

30. Ziyatdinova, G.; Yakupova, E.; Davletshin, R. Voltammetric determination of hesperidin on the electrode modified with $\mathrm{SnO}_{2}$ nanoparticles and surfactants. Electroanalysis 2021, 33, 1-12. [CrossRef]

31. Sun, B.; Hou, X.; Li, D.; Gou, Y.; Hu, F.; Li, W.; Shi, X. Electrochemical sensing and high selective detection of hesperidin with molecularly imprinted polymer based on ultrafine activated carbon. J. Electrochem. Soc. 2019, 166, B1644. [CrossRef]

32. Sun, D.; Wang, F.; Wu, K.; Chen, J.; Zhou, Y. Electrochemical determination of hesperidin using mesoporous $\mathrm{SiO}_{2}$ modified electrode. Microchim. Acta 2009, 167, 35-39. [CrossRef]

33. David, I.G.; Buleandra, M.; Popa, D.E.; Bîzgan, A.-M.C.; Moldovan, Z.; Badea, I.-A.; Iorgulescu, E.E.; Tekiner, T.A.; Basaga, H. Voltammetric determination of polyphenolic content as rosmarinic acid equivalent in tea samples using pencil graphite electrodes. J. Food Sci. Technol. 2016, 53, 2589-2596. [CrossRef]

34. Obendorf, D.; Reichart, E. Determination of hesperidin by cathodic stripping voltammetry in orange juice and Helopyrin, a phytopharmaceutical preparation. Electroanalysis 1995, 7, 1075-1081. [CrossRef]

35. Yardım, Y.; Keskin, E.; Sentürk, Z. Voltammetric determination of mixtures of caffeine and chlorogenic acid in beverage samples using a boron-doped diamond electrode. Talanta 2013, 116, 1010-1017. [CrossRef] [PubMed]

36. Sağlam, Ö.; Dilgin, D.G.; Ertek, B.; Dil, Y. Differential pulse voltammetric determination of eugenol at a pencil graphite electrode. Mater. Sci. Eng. C 2016, 160, 156-162. [CrossRef]

37. Alves, G.F.; Lisboa, T.P.; de Faria, L.V.; de Farias, D.M.; Costa Matos, M.A.; Matos, R.C. Disposable Pencil Graphite Electrode for Ciprofloxacin Determination in Pharmaceutical Formulations by Square Wave Voltammetry. Electroanalysis 2021, 33, 543-549. [CrossRef]

38. Laviron, E. General expression of the linear potential sweep voltammogram in the case of diffusionless electrochemical systems. J. Electroanal. Chem. 1979, 101, 19-28. [CrossRef]

39. Milicevic, A.; Novak Jovanovic, I. The relationship between the first oxidation potential and changes in electronic structures upon the electrochemical oxidation of flavonoids: Approach to O-glycosyl, galloyl and methoxy substituents. J. Mol. Liq. 2021, 335, 116223. [CrossRef]

40. Chiorcea-Paquim, A.; Enache, T.A.; Gil, E.D.S.; Oliveira-Brett, A.M. Natural phenolic antioxidants electrochemistry: Towards a new food science methodology. Compr. Rev. Food Sci. Food Saf. 2020, 19, 1680-1726. [CrossRef]

41. Hu, J.; Li, Q.; Tan, X. Study on the adsorptive behavior of hesperidin and its adsorptive stripping voltammetry. Anal. Lett. 1996, 29, 1779-1789. [CrossRef]

42. Temerk, Y.M.; Ibrahim, M.S.; Kotb, M. Square-wave cathodic adsorptive stripping voltammetric determination of 3hydroxyflavone, morin and hesperidin in bulk form and biological fluids in absence and presence of Cu(II). J. Braz. Chem. Soc. 2011, 11, 2056-2064. [CrossRef]

43. Wang, W.; Xu, X.; Bin, Q.; Ling, J.; Chen, G. A new method for fabrication of an integrated indium tin oxide electrode on electrophoresis microchips with amperometric detection and its application for determination of synephrine and hesperidin in pericarpium citri reticulatae. Electrophoresis 2006, 27, 4174-4181. [CrossRef] [PubMed]

44. Miller, J.N.; Miller, J.C. Statistics and Chemometrics for Analytical Chemistry, 5th ed.; Pearson Prentice Hall: Edinburgh, UK, 2005.

45. AOAC International. Appendix F: Guidelines for Standard Method Performance Requirements; AOAC International: Rockville, MD, USA, 2012; pp. 1-17.

46. Blasco, A.J.; Rogerio, M.; González, M.; Escarpa, A. “Electrochemical Index" as a screening method to determine "total polyphenolics" in foods: A proposal. Anal. Chim. Acta 2005, 539, 237-244. [CrossRef]

47. Phong, N.H.; Toan, T.T.T.; Tinh, M.X.; Tuyen, T.N.; Mau, T.X.; Khieu, D.Q. Simultaneous voltammetric determination of ascorbic acid, paracetamol, and caffeine using electrochemically reduced graphene-oxide-modified electrode. J. Nanomater. 2018, 2018, 5348016. [CrossRef]

48. Oliviera Brett, A.M.; Ghica, M.-E. Electrochemical oxidation of quercetin. Electroanalysis 2003, 15, 1745-1750. [CrossRef] 